
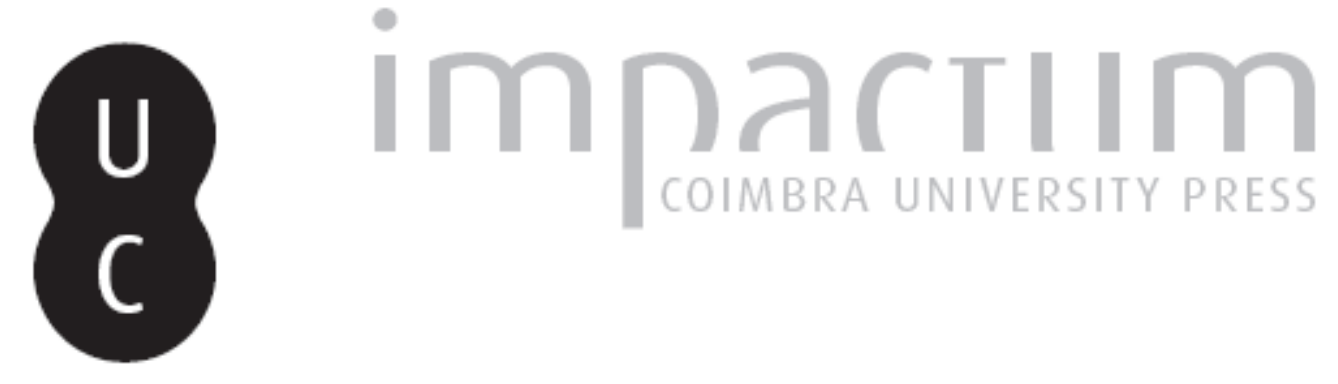

\title{
Risco e gestão do risco: questões filosóficas subjacentes ao modelo técnico conceptual
}

\author{
Autor(es): $\quad$ Almeida, António Betâmio de \\ Publicado por: Associação Portuguesa de Riscos, Prevenção e Segurança \\ URL \\ persistente: \\ URI:http://hdl.handle.net/10316.2/36045 \\ DOI: \\ DOI:http://dx.doi.org/10.14195/1647-7723_18_2 \\ Accessed : $\quad$ 26-Apr-2023 05:40:22
}

A navegação consulta e descarregamento dos títulos inseridos nas Bibliotecas Digitais UC Digitalis, UC Pombalina e UC Impactum, pressupõem a aceitação plena e sem reservas dos Termos e Condições de Uso destas Bibliotecas Digitais, disponíveis em https://digitalis.uc.pt/pt-pt/termos.

Conforme exposto nos referidos Termos e Condições de Uso, o descarregamento de títulos de acesso restrito requer uma licença válida de autorização devendo o utilizador aceder ao(s) documento(s) a partir de um endereço de IP da instituição detentora da supramencionada licença.

Ao utilizador é apenas permitido o descarregamento para uso pessoal, pelo que o emprego do(s) título(s) descarregado(s) para outro fim, designadamente comercial, carece de autorização do respetivo autor ou editor da obra.

Na medida em que todas as obras da UC Digitalis se encontram protegidas pelo Código do Direito de Autor e Direitos Conexos e demais legislação aplicável, toda a cópia, parcial ou total, deste documento, nos casos em que é legalmente admitida, deverá conter ou fazer-se acompanhar por este aviso.

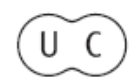




\section{territorium}

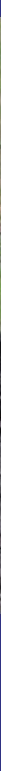

\section{Afirmar as Ciências Cindínicas}

Revista da Associação Portuguesa de Riscos, Prevenção e Segurança 


\section{territorium 18, 2011, 23-31}

journal homepage: http://www.nicif.pt/riscos/Territorium/numeros_publicados

RISCO E GESTÃO DO RISCO. QUESTÕES FILOSÓFICAS SUBJACENTES AO MODELO TÉCNICO CONCEPTUAL*

António Betâmio de Almeida

Professor Emérito, Universidade Técnica de Lisboa, Instituto Superior Técnico Membro da Academia de Engenharia de Portugal aba@civil.ist.utl.pt

\section{RESUMO}

Apresenta-se uma reflexão pessoal sobre questões filosóficas associadas ao risco e à gestão do risco no contexto do significado e das aplicações práticas.

Palavras chave: Risco, filosofia, gestão de riscos.

\section{RESUMEN}

Riesgo y gestión del riesgo. Cuestiones filosóficas subyacentes al modelo técnico conceptúale - Se presenta una consideración personal sobre cuestiones filosóficas asociadas a los conceptos de riesgo y gestión del riesgo en el marco de su significado teórico y de la práctica.

Palabras clave: Riesgo, filosofía, gestión de lo riesgo.

\section{RESUMÉ}

Risque et gestion du risque. Questions philosophiques subjacentes au modèle technique conceptuel - On présente dans ce travail une réflexion personnelle sur des questions philosophiques associées aux risques e à la gestion des risques en ce que concerne la signification et les pratiques des mêmes.

Mots-clé: Risque, philosophie, gestion des risques.

\section{ABSTRACT}

Risk and risk management. Philosophical questions inherent to the conceptual technical model - A personal thought about some philosophical questions related to risk and risk management process in the context of the meaning and of the applied practice are presented in this work.

Key words: Risk, philosophy, risk management.

\footnotetext{
* O texto deste artigo corresponde à comunicação apresentada ao II Congresso Internacional de Riscos e VI Encontro Nacional, tendo sido submetido para revisão em 01-06-2010, tendo sido aceite para publicação em 21-07-2010.

Este artigo é parte integrante da Revista Territorium, n. ${ }^{\circ} 18,2011$, ${ }^{\circledR}$ RIscos, ISBN: 0872- 8941.
} 


\section{Introdução}

O conceito de risco tem um lugar privilegiado na Sociedade contemporânea e tem acompanhado, de um modo mais ou menos consciente, a aventura da Humanidade na fazer frente a perigos e incertezas associados aos sucessivos futuros. Há, contudo, um razoável consenso em considerar a época do Renascimento, das descobertas e do comércio marítimo de longo curso como marcos na consolidação inicial de um modelo de análise de riscos. Na Idade Moderna, uma catástrofe numa capital europeia, o terramoto de 1755 em Lisboa, suscitou na Europa um debate de ideias sobre a providência e o destino. 0 evento fez desencadear, por parte do poder político, um conjunto de medidas para atenuar os efeitos sociais e acções de protecção contra a actuação futura de sismos. As decisões então tomadas podem ser consideradas como um exemplo histórico de resposta a uma calamidade natural e uma primeira organização de gestão de crise (A. AlmeIDA, 2005).

Em Portugal, a divulgação e a promoção da análise e gestão de riscos teve um incremento relevante a partir da década de 90 do século XX (e.g. A. Almeida e T. Viseu, 1997; A. Almeida et al., 2003; F. Rebelo, 2003; L. Lourenço, 2004). Actualmente, a gestão de riscos é encarada como um processo de actuação eficaz para responder a perigos e incertezas nos mais variados domínios da Sociedade. A protecção contra os perigos que possam afectar o público ou o ambiente passou a constituir um direito reconhecido e exigido pela opinião pública e um indicador da qualidade de vida e de cidadania.

Da aceitação resignada dos acontecimentos passou-se para uma fase de intervenção dos Estados na regulação da vida de actividades públicas e privadas, em defesa da saúde e segurança públicas, e para uma crescente responsabilização pelos efeitos resultantes do impacto dos diferentes perigos, de origem natural ou antrópica.

É pois, neste contexto, que o risco e a análise e gestão de riscos passaram a ocupar um lugar de relevo nas sociedades ocidentais. As características sociológicas e culturais do tipo de desenvolvimento destas sociedades, os efeitos emergentes da globalização e das alterações decorrentes da introdução de novas tecnologias e as ameaças planetárias intensificaram a importância do conceito risco. O risco tornou-se numa característica forte de ideologias dominantes nos domínios da economia, da política e do social. De tema "marginal" da sociedade, o risco passou a tema central e sofisticado, instrumento de "poder" no domínio de "futuros" e componente de discursos de "poder" e "contra-poder". A gestão do risco pode mesmo ser um exemplo de gestão de uma situação "imaterial", em sintonia com uma tendência saliente da economia contemporânea (A. GoRz, 2003).
Com Feuerbach, consideramos que o que numa obra humana tem capacidades para ainda vir a ser desenvolvido, e que merece vir a ser dito e questionado, pode ser considerado como o respectivo "elemento ou conteúdo filosófico". O objectivo do presente trabalho é desvelar capacidades e dificuldades através da colocação de questões suscitadas pela reflexão e experiências pessoais na promoção e aplicação da gestão e análises de riscos.

Adoptamos a dimensão negativa (perdas) dos riscos, de origem "natural ou tecnológica", por ser essa a característica específica da gestão dos riscos públicos e de outros riscos significativos para a vida humana.

\section{O risco, uma construção}

O risco é um conceito abrangente, motivador e ambíguo, com diferentes dimensões e uma potencialidade especial para:

- caracterizar ocorrências incertas associadas a desvios relativamente a situações de referência;

- justificar opções e acções, como variável de decisão;

- incentivar a protecção de pessoas e bens e melhorar, assim, a "qualidade de vida";

- constituir uma representação simbólica do “mundo contemporâneo".

Tendo este conceito diversas raízes, criadas em épocas e territórios muito distantes, e múltiplas dimensões humanas e sociais, é natural que os discursos e as teorias do risco, desenvolvidas por diferentes comunidades científicas e técnicas, (ainda) não sejam totalmente concordantes. Acresce que a estruturação científica dos processos de análise e de gestão de riscos incorpora termos muito conhecidos associados a comportamentos humanos (psicológicos), cujos significados são fluidos e foram sofrendo graduais e subtis alterações ao sabor dos tempos e dos contextos. A essa "herança", a postura fundadora dos pioneiros ou de grupos mais activos ou influentes tende a adicionar, de uma forma que não é destituída de lógica razoável, a convenção pragmática e a eficiência de uma economia elegante e formal.

A multifacetada evolução do que designamos por risco (P. BERNSTEIN, 1998) convergiu para um padrão tendencialmente consistente e bastante homogéneo, em particular, no que concerne a análise quantitativa do risco. A indústria de energia nuclear nos EUA veio suscitar uma forte estruturação da gestão e análise quantitativa do risco nomeadamente na forma desenvolvida para aplicações em engenharia (Relatório Rasmussen, publicado em 1974/5). As bases das ciências do perigo ou ciências cindínicas foram propostas (G. KERVERN, 1991) 
e uma primeira questão pode colocar-se: será adequada uma convergência total de conceitos, de formalismos e de processos?

Consideramos, como postulado de base, que o risco, no contexto do desenvolvimento e da estruturação racional da análise e da gestão do risco, é o resultado de uma "construção" mental associada a acontecimentos (eventos) ou processos potencialmente perigosos. Acontecimentos possíveis, mas de realização ou ocorrência incerta, considerados quando ainda não realizados, se alguma vez se realizarem.

Acontecimentos que têm lugar em cenários construídos com base no passado ou em processos lógicos de antevisão de situações que cumprem as condições aceites de possibilidade. É o que designamos por "Futuros Presentes" de ocorrência incerta. Estes acontecimentos estão associados a processos, ou cadeias de causalidade, através das quais um elemento perigoso se propaga com uma determinada intensidade e vai actuar (impacto ou agressão) em receptores expostos donde podem resultar consequências prejudiciais (danos).

A construção do conceito risco está, assim, intimamente ligada a três factores: Incertezas (na realização do acontecimento e nas respectivas condições e características de realização), Intensidade de actuação e Consequências, efeitos ou danos provocados pelo impacto nos receptores.

A sensação ou percepção “fluida” do perigo é insuficiente no quadro de um processo de decisão racionalizada, envolvendo diferentes alternativas, o qual exige uma variável que possa ser avaliada de um modo consistente e comparável.

Uma das preocupações fundamentais da construção em causa, tendo em conta os processos de decisão, decorre da necessidade de comparar, num presente, determinados efeitos cuja ocorrência em "futuros" é considerada com diferentes graus de incerteza ou de convicção. O conceito de probabilidade, com os seus diferentes significados ou perspectivas, surge, assim, associado ao risco e, em particular, à análise quantitativa do risco.

Frank Knight (1885-1927) defendeu com firmeza o seguinte princípio: risco implica conhecimento com probabilidades (mensurável), caso contrário é desconhecimento ou incerteza em sentido restrito (F. KNIGHT, 1921).

Assim, a construção da análise quantitativa do risco implica a graduação da plausibilidade de eventos incertos através da avaliação de probabilidades. No processo de construção, a prática e a reflexão permitiram reduzir os três factores intervenientes acima referidos (incerteza, intensidade, consequência) a dois:
- Probabilidades de ocorrência (caracterizando a incerteza da realização do processo perigoso com uma determinada intensidade).

- Consequências (caracterizando a intensidade do processo através dos danos ou perdas envolvidos).

De entre as diferentes propostas para a construção da variável de decisão caracterizadora do risco, consolidaram-se duas perspectivas fortes:

- Uma primeira perspectiva, centrada na ocorrência dos eventos ou dos processos perigosos que ultrapassam determinados limites, que define (Definição 1) risco como a probabilidade de ocorrência de um processo perigoso ou indesejável,

Risco $_{1}=$ Probabilidade de ocorrência ou de "falha"

Na engenharia, esta é a perspectiva da "teoria de fiabilidade" podendo a fiabilidade ser definida como a probabilidade de um componente ou sistema cumprir a sua função de modo adequado, segundo determinados critérios, por um determinado período de tempo e de acordo com determinadas condições de operação. Inscrevem-se nesta perspectiva o conceito clássico de "risco hidrológico" (probabilidade de excedência de uma determinada variável hidrológica) e outros tipos de abordagens nomeadamente na teoria das falhas e de manutenção de sistemas tecnológicos.

- Uma segunda perspectiva, centrada no valor das consequências possíveis, mas incertas, dando ênfase à necessidade de comparar danos ou perdas de situações alternativas, em ambiente de incerteza, com custos certos de medidas, que define (Definição 2) o risco como o "valor expectável” ou "esperança matemática" do valor do dano incerto,

$\mathrm{RiscO}_{2}=$ Probabilidade de ocorrência do processo x valor estimado do dano ou consequência

Nos processos envolvendo a análise quantitativa do risco é esta a definição que tende a ser adoptada.

Qual é a justificação desta definição?

Ela baseia-se no conceito de "esperança matemática" definida por C. Huygens em 1656, no contexto de problemas associados a "jogos de sorte", como sendo o "valor mais vantajoso para um jogador relativamente a potenciais ganhos ou perdas no futuro " ("Primeiro Tratado de Cálculo Aleatório”, publicado em 1657). Assim, o valor (D) estimado do dano é "reduzido" $\left(D^{*}\right)$, em função do grau de incerteza, pela multiplicação pela respectiva probabilidade $(\mathrm{P})$ de ocorrência: 


$$
\begin{aligned}
& \text { Risco }=D^{*}=P D \leq D \\
& \text { com } 0 \leq P \leq 1 .
\end{aligned}
$$

Deste modo, a variável risco tem um valor quantificável que pode ser comparado com outros num processo de apreciação e de decisão quantitativo. Riscos com natureza diferente (as unidades de risco quantitativo indicam o tipo de valor: vítimas/ano ou euros/ano, a título de exemplo) podem assim ser comparados por classes de consequências. Tem-se que reconhecer que a solução encontrada é simples e quase genial: o conceito tem resistido séculos! De Moivre, no seu livro “De Mensura Sortis”, publicado em 1711, explicita, pela primeira vez, este conceito do risco (Definição 2): “A medida do risco de perda de uma quantia é o produto do montante colocado em jogo pela probabilidade de perda" (P. Bernstein, 1998).

A expressão (2) é apresentada, actualmente, de diversas formas. Uma das mais eficazes na análise e na gestão de riscos quantitativas é a seguinte (A. Almeida, 2011):

$$
\text { Risco }=P_{1} \times P_{2} \ldots .(E \times V) \text {. }
$$

onde $\mathrm{P} 1$ = probabilidade de realização do processo perigoso com determinadas características, $\mathrm{P} 2=$ probabilidade (condicionada) de ocorrerem determinadas consequências resultantes do impacto, $\mathrm{E}=$ Exposição ou valor total exposto ao impacto (receptor), $\mathrm{V}=$ vulnerabilidade (física) dos receptores expostos $(0<\mathrm{V}<1)$, também designado, em alguns domínios, por operador de danos ou de "Fragilidade", o qual caracteriza a perda de valor resultante do impacto. Salienta-se que a distinção entre Exposição (ainda sem danos ou “vulnerável” em potência) e Vulnerabilidade física (operador de danos em acto), função da intensidade do impacto em cada cenário, é de grande eficácia operacional e uma base para enquadramento de medidas de mitigação (J. DougLAS, 2007).

Com a definição 2, a análise quantitativa do risco possibilita a consideração e a internalização dos riscos em análises de "custo-benefício" e em processos multicritérios quantitativos de decisão. Esta capacidade é apreciada nos projectos de sistemas tecnológicos complexos ou no planeamento de medidas de protecção dispendiosas contra riscos naturais.

\section{Equivalências de narrativas descritivas}

A análise quantitativa faz uso, de um modo muito marcante, da descrição matemática dos processos que traduzem o desenrolar dos cenários. A prática tem feito sugerir diversas definições de conceitos ou de grandeza associados ao risco e à análise e gestão do mesmo.

Em geral, constata-se que é possível uma equivalência de descrições entre a descrição matemática e outros tipos de descrições não matemáticas. A título de exemplo, considere-se o termo "susceptibilidade" ou “...a propensão ou a tendência de uma zona ser afectada fisicamente por um perigo..." (J. CANTOS et al., 2002) que pode ser expresso do seguinte modo, utilizando uma probabilidade condicionada:

$$
\mathrm{S}=\operatorname{prob}\left(\mathrm{V}>0 \mid \mathrm{I}_{0}, E_{0}\right)
$$

Ou, para i cenários,

$$
\mathrm{S}=\sum_{i}^{N} \operatorname{prob}_{\mathrm{i}}\left(\mathrm{V}_{\mathrm{i}}>0 \mid \mathrm{I}_{\mathrm{i}}, E_{i}\right)
$$

Em que $S$ = susceptibilidade, $V=$ vulnerabilidade física, $\mathrm{I}$ = intensidade do agente perigoso e $\mathrm{E}=$ valor exposto na zona potencialmente afectada, para um cenário isolado (expressão (5)) ou para um conjunto de $\mathrm{N}$ cenários (expressão (6)).

Contudo, o significado e a emoção associadas a uma narrativa ou descrição não poderão ser totalmente transcritos, e sentidos, para uma linguagem matemática. Para além de poder ser redutora a exigência de quantificar valores, a operacionalização do conceito pode revelar-se difícil, nomeadamente no que respeita o cálculo ou a estimação de probabilidades: para ultrapassar algumas das dificuldades sem perda de eficácia, é frequente a consideração de classes de probabilidades, caracterizadas por opiniões subjectivas, e a aplicação de matrizes de risco com a quantificação qualificativa da importância de danos ou ainda de caracterização baseada em lógicas difusas. A representação gráfica, por classes e por cores, tenta amenizar de certo modo algumas barreiras de comunicação na análise quantitativa.

Sem dúvida que, no contexto de um processo de decisão racionalizado, a análise e a avaliação quantitativa é útil, mas não é o único modo de caracterização de uma situação de risco. Existem mesmo perspectivas opostas: Mary Douglas insistiu que o risco não pode ser um conceito objectivo e mensurável mas sim um conceito construído social, cultural e politicamente: o risco não deveria ser reduzido a uma dimensão técnica (M. DougLAs, 1985 e 1992; M. Douglas et al., 1982).

É, em nosso opinião, uma exigência ética que se afastem fundamentalismos, se lancem pontes e se compreendam os significados substantivos no sentido de ser possível desenvolver trabalhos multidisciplinares.

\section{Gestão do risco}

\section{“Mais vale prevenir do que remediar"}

Este aforismo pode ser um bom exemplo de filosofia prática e popular. Quase tudo o que é essencial para um comportamento humano sensato está dito nesta frase geral, aplicável a todas as situações de perigo: 
- Uma apreciação comparativa, valoração (ética) da antecipação e critério de decisão ("mais vale”).

- A actuação proposta, para um qualquer presente, de modo a evitar um "futuro" associado a um cenário de perigo ("prevenir").

- Avaliação de potenciais consequências e de medidas de recuperação do valor (geral) exposto ("remediar”).

0 aforismo pressupõe a possibilidade da percepção de um perigo que se pode vir a estruturar em risco e a realizar-se mas que pode ser eliminado por uma acção antecipada. Na verdade, cada ser humano aplica, no quotidiano, de um modo mais ou menos consciente, tácticas de avaliação de situações de risco, ou perigosas nos actos de decisão relevantes para a sua sobrevivência e desenvolvimento.

Esta possibilidade automática deixou de ser a característica normal na sociedade contemporânea. Os perigos tornaram-se difusos e são dificilmente percepcionados numa sociedade fortemente dependente de sistemas e conceitos de tal complexidade que a maioria dos cidadãos não pode entender as vulnerabilidades e os perigos associados. É um dos aspectos da designada “sociedade de risco" (U. BECK, 1986, 1999, 2000 e 2001) e tema de análises culturais (A. GIDDENS, 1990 e 2002; N. Luhmann, 1993). A estruturação do processo desde a identificação até à decisão e à implementação de medidas torna-se então necessária. É a função da análise e da gestão de riscos.

Esta estruturação foi muito influenciada pelos desenvolvimentos nas áreas da gestão financeira $e$ de gestão de seguros durante o séc. XX. A título de curiosidade, registe-se que o temo "risk manager" é proposto em 1956 na Havard Business Review num artigo de Russel Gallagher (R. Gallenger, 1956) tendo, desde então, vindo-se a impor um quadro organizativo geral que inclui a análise de riscos e a gestão de crises.

De acordo com a recente norma internacional ISO 31000 "Risk Management Principles and Guidelines" (2009), a gestão de riscos compreende o "conjunto de actividades para orientar e controlar uma organização no que respeita o risco". No comportamento futuro de um sistema natural ou construído (e.g. um produto tecnológico) somos levados a admitir um padrão normal de expectativas, um estudo de referência ou um conjunto de objectivos a cumprir. Diz-nos a experiência que estas condições, estas expectativas, nem sempre se cumprem: acontecimentos, previsíveis ou não, podem ocorrer num futuro mais ou menos próximo e provocar "desvios" no esperado com consequências (positivas ou negativas. De acordo com este quadro conceptual, consistente com a Definição 2 de risco, a referida norma ISO define risco do seguinte modo: "efeito da incerteza nos objectivos".
Esta definição alerta-nos, de uma forma elegante, para a necessidade de identificar os objectivos que se pretendem atingir (e.g. a preservação da vida humana), as incertezas a considerar (epistémicas e aleatórias) e os efeitos ou consequências prováveis.

Numa gestão de riscos não se prevê o futuro que irá ocorrer mas consideram-se diversos cenários de "futuros" possíveis ou plausíveis e avaliamse as respectivas probabilidades de ocorrência e as potenciais consequências, tangíveis ou nãotangíveis. O processo de aplicação de uma gestão de riscos compreende um conjunto de procedimentos e de componentes e um formalismo de análise quantitativa relativamente consensual (Fig. 1). Podem existir diferenças de léxico (avaliação /apreciação; cálculo/estimação; perigo/risco; vulnerabilidade/ fragilidade; vulnerabilidade/susceptibilidade, a título de exemplo) nomeadamente na tradução de alguns termos mais relevantes ("assessment"/"evaluation"; "hazard"/"danger"/"threat"; “chance"/"probability", a título de exemplo) mas, no essencial, os conceitos podem ser entendidos, sem prejuízo de uma análise crítica e de adaptações adequadas a cada domínio de aplicação. Não é, contudo, um processo técnico trivial pois baseia-se num conceito imaterial (o risco) com reflexos em medidas e acções bem reais. 0 referido processo é a base de programas de acção e de organização nos mais diversos aspectos da sociedade contemporânea.

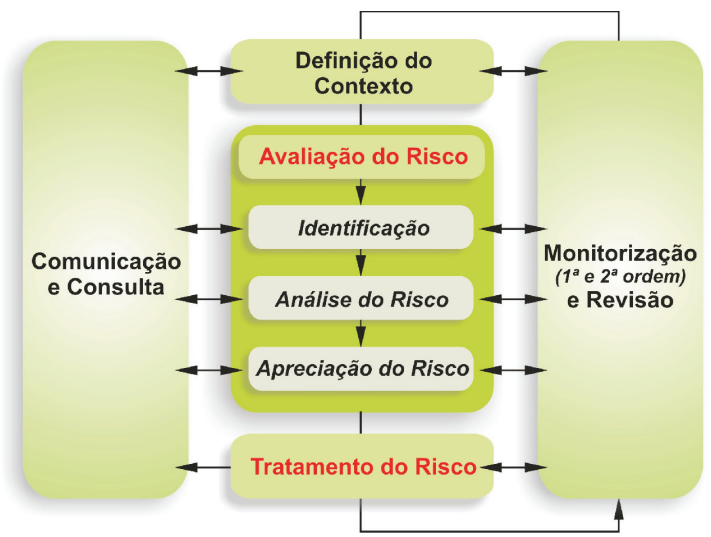

Fig. 1 - Processo geral da gestão do risco segundo a Norma ISO 31000:2009.

\section{Filosofias e questões filosóficas}

Centradas num conceito multidimensional, imaterial e difuso, a análise e a gestão de riscos são susceptíveis de serem objecto de reflexões filosóficas baseadas em temas muito diversos tais como:

- significados, realidade e objectividades;

- perigo, medo, tabu, segurança, valor e sociedade;

- epistemologia, indeterminismo, ignorância, incerteza e causalidade; 
- possibilidade, aleatoriedade e probabilidade;

• precaução, prevenção, protecção e remediação;

- moral, ética e responsabilidade;

- aceitação e tolerabilidade ao risco.

De entre estes termos, destacamos, como nucleares e permanentemente actuais, o aprofundamento do acontecimento aleatório (e.g. A. Cournot, 1851 e T. MARTIN, 1996) e os diferentes significados das probabilidades (D. Gillies, 2000; I. Hacking, 2002; H. Landemore, 2004; M. GalavotTI, 2005)).

1 - Na dimensão da análise quantitativa, a definição 1 do risco parece ser consensual ou mesmo estar "fixada". Assim, como foi referido, o valor de um risco corresponde ao "valor expectável ou esperança matemática das consequências (perdas ou danos) associadas aos diferentes cenários i considerados na análise:

$$
\text { Risco }=\mathrm{E}(\text { perdas })=\sum^{\mathrm{N}} P_{i} D_{i}
$$

É um conceito que responde à questão da atribuição de um valor "objectivo" às potenciais perdas futuras com realização incerta, exigida pelo processo de decisão racionalizado, mas que tem ainda uma capacidade inerente especial: a equivalência do valor de risco em situações diferentes. Com efeito, as expressões (4) e (7) indicam que, para cada cenário, o risco se manterá com um valor constante no caso do produto $P$ D se mantiver constante. Isto significa que, neste quadro de avaliação quantitativa, existe um contínuo de situações envolvendo probabilidades baixas e danos elevados até probabilidades elevadas e danos baixos em que o risco se mantém. Esta variação seguiria uma relação hiperbólica no plano probabilidades/consequências. Será este conceito o mais adequado, abrangente ou útil em todas as situações? A percepção e aceitação social de um valor concreto de risco não é indiferente aos diferentes pares de valores PD, mesmo quando o valor quantitativo do risco se mantém constante pela definição 2 (P. SLOVIC, 2001). O valor absoluto de determinado tipo de consequência pode influenciar a disponibilidade para aceitar um determinado nível de risco calculado. A psicologia social fornece elementos para esta análise e os critérios gerais de aceitação social de riscos têm, em geral, em consideração esta variação de comportamento. Acresce ainda a dificuldade em integrar danos tangíveis e intangíveis. Não será uma "falha” da definição técnica?

2 - A estimação de probabilidades da ocorrência, e das cadeias de causalidade associadas aos cenários, constitui um aspecto central da análise quantitativa do risco. Constitui, também, uma dificuldade em muitos casos práticos, nomeadamente quando não existem dados referentes a comportamentos análogos (séries) no passado ou quando não se tem um conhecimento seguro do "processo de geração" do perigo e da sua propagação (cadeias de causalidades e resposta). É o caso de cenários associados a eventos isolados únicos, para os quais a interpretação frequencial directa não é possível. 0 recurso a probabilidades de tipo subjectivo, à decomposição “forçada" do cenário em componentes causais elementares com probabilidades relativamente conhecidas ou, ainda, à selecção de conjuntos de casos considerados semelhantes e com frequências mais fáceis de estabelecer, torna-se, então, inevitável mas coloca a questão sobre o significado da probabilidade, ou mesmo da validade do conceito de probabilidade a um evento único.

Uma outra situação difícil é a dos cenários associados a acontecimentos raros ou com valores extremos de variáveis aleatórias. As probabilidades correspondentes a estes casos, nomeadamente as probabilidades com valores muito pequenos, colocam questões de significado e de interpretação prática, nomeadamente no caso da apreciação de investimentos em medidas de mitigação. Haverá um limiar inferior da probabilidade a partir do qual o acontecimento pode ser considerado impossível? (discussão exaustiva em A. Cournot, 1851 e T. MARTIN, 1996).

3 - É frequente, nos cenários de catástrofes ou de acidentes com infra-estruturas importantes, a probabilidade de falha ser muito pequena mas os danos associados serem muito elevados. Na expressão (7), as incertezas nos valores de P e D reflectem-se em elevadas sensibilidades do valor de risco tornando a apreciação do mesmo muito difícil.

Nas infra-estruturas complexas de engenharia é frequente obterem-se para probabilidades de falha ou de rotura valores da ordem de $10^{-6}$ ou $10^{-8}$ (para a central atómica de "Three Miles Island" o valor era de $1 / 17$ 000). Na engenharia, é difícil atingir, com garantia, objectivos com probabilidades inferiores a $10^{-6}$. Será admissível ou prudente considerar estes eventos impossíveis?

4 - A modelação computacional de sistemas muito complexos permite a "previsão" de efeitos e a simulação de cenários para avaliação de riscos. A complexidade e os horizontes de tempo muito longos introduzem incertezas de tipo epistémico (ignorância ou conhecimentos insuficientes), erros e omissões. A modelação de cadeias de causalidade não tem, em geral, em consideração o comportamento humano dificilmente modelável a longo prazo (V. KEYSER, 2002).

Aceitar sem "limites" os resultados de modelos complexos é um "perigo" acrescido: a "razão” pode 
esquecer os limites do razoável e quando a gestão dos riscos se confunde com uma gestão de risco, a sociedade está duplamente em perigo! A gestão dos riscos associados a produtos financeiros sofisticados antes da crise de 2008 é um exemplo paradigmático da falta de controlo nos limites de modelos muito complexos e do seu afastamento da "realidade" (R.P. Drolt et al., 2010).

Não sendo os modelos "a realidade", até onde podem ser considerados fiáveis como suporte de decisões fundamentais? A consideração de incertezas e limitações inerentes aos modelos complexos é pois uma exigência.

5 - Um processo de gestão de riscos não é axiologicamente neutro e pode interferir com valores sociais e culturais, colocando a questão da responsabilidade ética e moral. Os critérios de aceitação ou de tolerabilidade pública dos riscos são componentes importantes e facilitadores do processo de decisão e de responsabilização mas não podem ser considerados como simples produtos racionais.

As questões relativas aos critérios de apreciação envolvendo probabilidades de ocorrência e consequências que se podem colocar são, entre outras, as seguintes:

- Poderão ser universais e válidos para qualquer tipo de risco ou deverão ser específicos, em função do tipo de perigo e de efeitos?

- Poderão ser absolutos ou deverão resultar de processos de escolha entre opções alternativas? Será mesmo admissível considerar uma aceitação de um risco acrescido ou o que se aceita são sempre opções?

6 - Em situações de risco público com elevada exposição pública e danos potenciais catastróficos (e.g cenários de epidemias ou de calamidade generalizada) verifica-se uma tendência marcante: a de "exagerar" a ameaça, desvalorizar ou mesmo abandonar a avaliação de probabilidades e mitigar vulnerabilidades como se o pior fosse mesmo acontecer ("catastrofismo esclarecido" - J. Dupuy, 2002).

O princípio da precaução, inicialmente um princípio de gestão ambiental, passou, também, a ser um princípio de gestão de crises no caso de não existir uma "absoluta" certeza científica para concluir que o evento perigoso vai ou não provocar os danos estimados. 0 enfraquecimento da componente racional pode ter custos relevantes: o custo desproporcionado de medidas e a frustração colectiva caso as previsões se afastem da realidade.

7 - Cultura do risco ou cultura de risco? Uma ambiguidade de valores, de conceitos e de mensagens na representação da relação da Sociedade com o risco (uma "gestalt"?)

Por um lado a exaltação social da atitude ousada e capaz de transgredir e ultrapassar limites ou fronteiras; por outra a apreensão pela falta de segurança e a crítica por ausência de uma cultura do risco e por um défice de prevenção e protecção. Esta dupla atitude social será a mais indicada para o desenvolvimento dos processo de gestão de riscos?

8 - 0 risco tem múltiplas dimensões (política, cultural, psicológica, sociológica, jurídica, administrativa, organizacional...) e aparece no Ocidente (e no Mundo) contemporâneo como uma representação simbólica forte.

De um ponto de vista filosófico, o risco parece seguir na esteira da tecno-ciência: está em todo o lugar e em nenhum, ninguém o viu, ninguém o verá! Na verdade vai "dominando" a nossa vida e o nosso olhar do “mundo" (F.D. SEBBAH, 2010).

$\mathrm{O}$ (s) risco(s) integrado(s) na "realidade do quotidiano", "exigem", através do modelo de gestão, a racionalidade e a eficácia técnico-científica e constituem-se como factores condicionantes e estruturantes da Sociedade (à Foucault). Esta representação reforça o "mundo da razão" em "confronto" com o "mundo sensível” aos perigos.

9 - O paradigma científico tem mudado e, actualmente, uma parte significativa da comunidade científica tem uma influência muito forte na opinião pública e nos "poderes". A capacidade de previsão e de realização sucessiva do previsto forneceu uma representação forte de poder e de capacidade de acção às metodologias científicas que superou outras alternativas. A análise quantitativa do risco baseia-se na aplicação de metodologias científicas aos cenários de "futuros" e às respectivas cadeias de causalidade. o nosso conhecimento científico não é completo e a procura de "verdade científica" é uma das características da atitude científica. A generosidade e a vontade de influenciar positivamente o curso das decisões humanas coloca ao cientista desafios e a "verdade científica" é colocada em confronto com a "utilidade científica". Para se ter influência e recursos recorre-se a redes de colaboração e, gradualmente, tende a instalar-se um clima de "consenso" (forçado) de convicção e de intervenção o qual pode vir a sobrepor-se ao "tempo" natural de desenvolvimento e consolidação dos conhecimentos. A "crença”, a representação psicológica, podem, então, tornar-se atitudes e respostas relevantes. A base de sustentação do "científico" é mesmo alargada a diferentes comunidades "profanas" ("não-científicas”), com implicações (pressões) nas decisões políticas. 
Esta passagem gradual de um tipo de sustentação para outro constituirá um sinal de decadência do posicionamento científico? Poderá ainda existir uma "praxis" científica capaz de se sobrepor à dependência financeira ou à vontade de poder de protagonismo excessivos? A institucionalização globalizada da ciência deverá ter limites?

\section{Conclusão}

As metodologias de análise e de gestão de riscos não podem substituir totalmente outras formas de aplicar os conhecimentos e de tomar decisões que sejam consideradas eficazes.

Em particular, a análise quantitativa de riscos, não obstante os grandes benefícios que a sua aplicação pode trazer em determinados contextos, não deve ser considerada de uma forma redutora ou como uma panaceia para garantir "seguranças" quase absolutas.

As referidas metodologias têm a seu favor o facto, muito positivo, de colocarem as consequências ou os efeitos incertos, resultantes de uma exposição a um perigo, no centro das decisões. Podem, assim, contribuir para se evitarem danos ou perdas irreparáveis a terceiros e, de um modo global, à Sociedade.

Uma decisão (ou a elaboração de um projecto) "informada" pela análise dos riscos associados pode, assim, ser enriquecida com uma visão mais alargada e responsável relativamente aos acontecimentos "futuros".

Contudo, a análise e a gestão de riscos não devem ser "encaixados" em estruturas rígidas ou dogmáticas e geradoras de ilusões ou de novos mitos relativos a uma racionalidade e eficiência sem limites numa deriva para uma Sociedade não-humanizada.

Uma deriva para narrativas estereotipadas das situações e para a produção de instrumentos meramente formais (e.g. a "burocracia do risco") desvirtuará o conceito e a eficácia da gestão e análise de riscos?

As análises quantitativas "devem" ser complementadas por narrativas mais completas ou diversificadas, com um maior espectro de sensibilidades, nomeadamente no que diz respeito ao comportamento e ao sentir humanos.

A gestão de riscos é, na realidade, uma forma de gestão de incertezas e de expectativas inerentes à nossa condição (humana), à insaciável "vontade de poder" mas é, também, uma tentativa de resposta organizada à(s) angústia(s) e revolta(s) pela nossa finitude e pelo sentimento de "perda" inevitável.

O diálogo e a compreensão das diferentes perspectivas associadas e estruturadas em termos do(s) risco(s) é uma forma inteligente de ganho para todas as partes envolvidas. O tempo e a prática julgarão, com todo o respeito, as diferentes convicções em jogo. É essencial lançar "pontes" entre escolas ou áreas científicas diferentes e com interesse na análise e gestão de riscos.

As respostas a estas e às outras questões colocadas surgirão em resultados de reflexão e de discussão, cada um irá propondo respostas...

\section{Referências bibliográficas:}

Almeida, A. B., Ramos, C. M., Santos, M. A., Viseu, T. (2003) - "Dam Break Flood Risk Management in Portugal”. LNEC, Lisboa, 265 p.

AlmeidA, A. B. (2005) - "The 1755 Lisbon Earthquake and the Genesis of the Risk Management Concept". International Conference 25 $5^{\text {th }}$ Anniversary of the 1775 Lisbon Earthquake, Proceedings, Novembro, Lisboa, pp. 57-64.

AlmeidA, A. B. e Viseu, T. (1997) - "Dams and Safety Management at Downstream Valleys". (Editors),A.A. Balkema, Rotterdam,247p.

Almeida, A. B. (2011) - "Incertezas e Riscos. Conceptualização Operacional”. Esfera do caos, 237p.

BECK, U. (1986) - "Risk society. Towards a New Modernity”. Sage Publications (edição 2003), 260 p.

BECK, U. (1999) - “World Risk society”. Polity (edição de 2003), 184 p.

BeCK, U. (2000) - "Risk society Revisited: Theory, Politics and Research Programs". The Risk Society and Beyond (B. Adam, U. Beck e J. Van Lonn, editors), Sage Publications (edição de 2005), pp. 211-229.

BECK, U. (2001) - "Un Mondo a Rischio". Discurso na Duma de Moscovo publicado pela Einaudi, Torino (2003).

Bernstein, P. L. (1998) - “Against the Gods. The Remarkable Story of Risk”. J. Wiley, New York, 383 p.

Cantos, J. O. e Ayala-Carcedo (2002) - "Riesgos Naturales. Conceptos fundamentales y clasificación”. In Cantos, J. O e Ayala-Larcedo, F. Javier (Ed.) - Riesgos naturales, Ariel Ciencia, Barcelona, pp. 41-74.

Cournot, A. (1851) - "Essai sur les Fondements de nos Connaissances”. Vrin (edição de 1975).

Douglas, J. (2007) - "Physical Vulnerability Modelling in Natural Hazard Risk Assessment”. Nat. Hazards 
Earth Syst. Sci., 7, pp. 283-288.

Douglas, M. (1985) - "Risk Acceptability According to the Social Sciences". New York, Russel Sage Foundation.

Douglas, M. (1992) - "Risk and Blame: Essays in Cultural Theory". London, Routlege.

Douglas, M. E Wildavsky, A. (1982) - "Risk and Culture". Berkeley, University of California Press.

Droit, R. P. e HenRot, F (2010) - "Le Banquier et le philosophe”. Le philosophe, Plon, $216 \mathrm{p}$.

Dupuy, J. P. (2002) - “Pour un Catastrophisme Éclairé. Quand l'impossible est certain". Edition du Seuil, 216 p.

Gallagher,R.,(1956)- "Risk Management:A New Phase of Cost Control". Harvard Business Review (Vol. 34), pp.75-86.

Galavottı, M. C. (2005) - "Philosophical Introduction to Probability”. CSLI Publications, 265 p.

Giddens, A. (1990) - "As Consequências da Modernidade". Celta Editora (edição portuguesa, $4^{a}$ Edição, primeira reimpressão, 2000), $126 \mathrm{p}$.

Giddens, A. (2002) - "Runaway World. How Globalisation is Reshaping our Lives". Profile Books, 104 p.

GILlies, D. (2000) - "The Philosophical Theories of Probability". Routledge, 223 p.
Gorz, A. (2003) - “L'Immatériel”. Galilée, Paris, 153 p.

HACKING, I. (2002) - “L'Émergence de la Probabilité". (edição francesa) Senil, 276 p.

KeYser,V. (2002) - “Qui a Peur de l'Erreur Humaine ?”. Labor, Col La Novia, 131 p.

Kervern, G. Y. e Rubise, P. (1991) - “L'Archipel du Danger. Introduction aux Cindyniques". CPE Economica, $444 \mathrm{p}$.

KNIGHT, F. H. (1921) - “Risk, Uncertainty and Profit”. Hort, Schaffner and Marx Co., Boston.

Landemore, H. (2004) - "Hume, Probabilité et choix raisonnable”. PUP, Philosophies, $127 \mathrm{p}$.

Lourenço, L. (2004) - "Riscos Naturais e Protecção do Ambiente”. F.L.U.C., Colecção Estudos, 180 p.

Luhmann, N. (1993) - "Risk. A Sociological Theory”. Aldine Transaction (edição de 2005), 236 p.

Martin, T. (1996) - "Probabilités et Critique Philosophique selon Cournot”, Vrin, 362 p.

Rebelo, F. (2003) -“ Riscos Naturais e Acção Antrópica. Estudos e Reflexões”. (2 Edição), Imprensa da Universidade, Coimbra, 286 p.

Sebbah, F. D. (2010) - "Une Thése Epistémologique ou la Fille du Diable ?”. Encre Marine, 189 p.

SLovic, P. (2000) - “The Perception of Risk”. Earthscan (terceira impressão, 2002), 473 p. 